GRADIATION\&APPLICATIONS

ISSN 2466-4294 (online) | rad-journal.org

Vol. 2 | Issue 2 | pp. $90-93,2017$

doi: 10.21175/RadJ.2017.02.020

Original research paper

\title{
THE STUDY OF BIOLOGICAL EFFECTIVENESS OF U-70 ACCELERATOR CARBON IONS USING MELANOMA B-16 CLONOGENIC ASSAY*
}

\author{
Evgeny Beketov $^{1,2^{* *}}$, Elena Isaeva ${ }^{1}$, Egor Malakhov ${ }^{1,2}$, Nadezhda Nasedkina $^{1}$, \\ Sergey Koryakin', Stepan Ulyanenko', Alex Solovev',2, Anatoly Lychagin'
}

${ }^{1}$ A. Tsyb Medical Radiological Research Center - Branch of the National Medical Research Radiological Center of the Ministry of Health of the Russian Federation, Obninsk, Russia

${ }^{2}$ Federal State Budget Institution "State Scientific Center of the Russian Federation - Institute for High Energy Physics”, Protvino, Russia

\begin{abstract}
The study was carried out using the system of accelerators (I-10o, U-1.5, U-7o). Ultra-precise equipment to position biological objects was applied. The dependency of melanoma B-16 cells survival on the dose of ${ }^{12} C$ ion irradiation was obtained. The carbon beam was studied within three main ranges: Bragg peak, areas before and after the peak. Dose dependence in the peak and in the area before the peak had a distinct linear pattern. In the distal part of the Bragg peak, linear-quadratic dependence was observed. Carbon ions RBE were 4.5, 1.7 and 2.4 for the peak, the areas before and after the peak, respectively.
\end{abstract}

Key words: Carbon ions, high-LET radiation, radiotherapy, $U-70, R B E$, clonogenic assay, melanoma $B 16$ cells

\section{INTRODUCTION}

Carbon ion therapy is one of the most promising methods in oncology. Its advantage over the conventional radiotherapy is proved for tumors of different etiology. According to some studies [1, 2], carbon ions are more appropriate for head and neck tumors, lung cancer, prostate and hepatocellular carcinomas. It is shown in simulation study [3] that carbon ions are more effective comparing to protons in case of deep-seated tumors with a diameter of up to $4 \mathrm{~cm}$.

The action of carbon ions on biological tissue as well as the exposure of any other ions due to specific energy transfer patterns should be described by at least three main areas. Range A is the plateau area before the Bragg peak (linear energy transfer - LET in case of used in the study system of accelerators $10 \div 16 \mathrm{keV} / \mu \mathrm{m})$. The second area - range $\mathrm{B}$ is the Bragg peak (LET was $180 \pm 26 \mathrm{keV} / \mu \mathrm{m}$ ). Range C follows the Bragg peak and can have almost the same LET $(20 \pm 1 \mathrm{keV} / \mu \mathrm{m})$ as in Range A.

Available data on biological effectiveness of carbon ions are mainly related to ranges $A$ and $B[1,4-7]$. Range $\mathrm{C}$, the area that follows the peak, has not been studied enough. It is also supposed that radiobiological effects in this area are insignificant. However, range $\mathrm{C}$ conforms the area of the healthy tissues located behind the target (tumor) and doses related to the area have to be taken into consideration while planning radiotherapy.

The subject of the present study was a precise estimation of the biological effectiveness of the carbon ion beam according to tumor cell survival.

\section{MATERIALS AND METHODS}

\subsection{B-16 cells}

The studies were carried out using mice melanoma B-16 cells. The cell culture was irradiated in the monolayer condition in the late log phase. In the course of irradiation, cell cultures were in 25 or $75 \mathrm{~cm}^{2}$ flasks (Corning, USA) containing RPMI-1640 medium (Paneko, Russia) and 2\% fetal calf serum (Biosera, France).

Melanoma is one of the most aggressive tumors, with high growth rates. According to some data [8] melanoma is considered as cell line with low radiosensitivity and an appropriate choice for conventional fractionation schemes. The used cell clone was B16F10. In accordance with our estimates the cell culture doubling time was $11 \pm 3$ hours, cell density in monolayer was $1423 \pm 72$ cells per $\mathrm{mm}^{2}$, cell diameter (suspension condition) - $14 \pm 2 \mu \mathrm{m}$. This mice melanoma cell clone according to some data [9] could

\footnotetext{
* The paper was presented at the Fifth International Conference on Radiation and Applications in Various Fields of Research (RAD 2017), Budva, Montenegro, 2017.

*beketov.ee@yandex.ru
} 
be considered as more metastatic (and thus more radio-resistant) than standard B16 cell culture.

\subsection{Clonogenic assay}

Survival of the irradiated cells was estimated by cell clonogenic activity. After the irradiation, cells were removed from the plastic surface of the flasks using a trypsin solution with $0.25 \%$ EDTA (Paneko, Russia). The cells were resuspended in RPMI-1640 medium and counted. Afterwards, cells were seeded (from 1000 to 140 ooo cells depending on the dose) in $100 \mathrm{~mm}$ Petri dishes (Corning, USA) containing RPMI-1640 medium and $10 \%$ fetal calf serum. Petri dishes were then kept in an incubator (Sanyo, Japan) with $5 \% \mathrm{CO}_{2}$ at $+37^{\circ} \mathrm{C}$ for 8-10 days until the formation of visible colonies.

At the end of the incubation and colony growth, the medium was removed and cell colonies were stained with $2 \%$ solution of methylene blue in $50 \%$ ethanol [10]. Counting of the colonies was conducted using a manual counter (Interscience Scan 100, France). An irradiated cell was considered alive if its colony consisted of at least 50 cells. The survival fraction for a certain dose was determined by dividing the number of living cells by the total number of seeded cells. The survival endpoint was calculated as a ratio of irradiated and non-irradiated cells' survival fractions.

The relative biological effectiveness (RBE) of the radiation was estimated as a ratio of iso-effective doses of studied and standard exposures.

\subsection{Irradiation sources and procedures}

The source of the unmodified (not spread-out) carbon ion beam was the system of accelerators: I-100, U-1.5, U-70 of the Institute for High Energy Physics (Protvino, Russia). The average ion energy was $\sim 455.8 \mathrm{MeV} /$ nucleon. The dose rates were $0.1,0.2$ and $0.05 \mathrm{~Gy} / \mathrm{min}$ in range $\mathrm{A}, \mathrm{B}$ and $\mathrm{C}$, respectively. Irradiation doses were 2.2-5.3 Gy in range A (plateau before the Bragg peak), 0.6-3.8 Gy in range B (Bragg peak) and 1.4-4.0 Gy in range $\mathrm{C}$ (area after the peak).

The standard exposure to gamma-rays was provided by ${ }^{60} \mathrm{Co}$ with an average energy of $\sim 1.25 \mathrm{MeV}$. The dose rate was $\sim 1.0 \mathrm{~Gy} / \mathrm{min}$, and the dose range was 2.0-10.0 Gy.

In the course of irradiation with ions, the flask with the cells was located in the air chamber, vertically and perpendicular to the beam. This chamber was, in turn, a moveable part of a bigger container filled with water (a necessary condition to form the ion specific energy transfer pattern). This two-chamber system was completed with the equipment for ultra-precise movement of the objects (Figure 1).

Comprehensive schemes of the irradiation equipment, dosimetry and monitoring devices, and a technique for irradiation have been published earlier [11].

Cell irradiation with gamma-rays was carried out without the described object moving system. The flask with the cells was located horizontally and perpendicular to the source of gamma-rays.

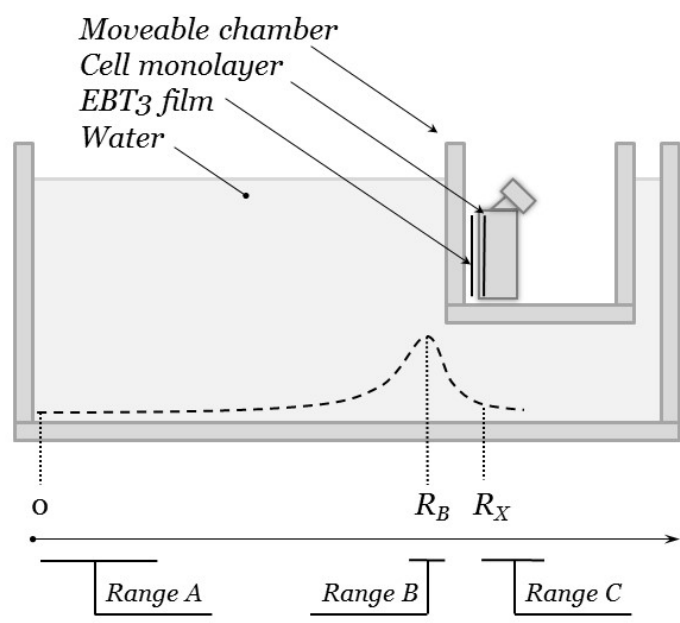

Figure 1. Two-chamber system for biological object irradiation with carbon ions: $R_{x}$ - distance between the cell monolayer and the beginning of water layer, $R_{B}-$ Bragg peak location

\subsection{Statistics}

The cell survival data was processed using the statistical software $\mathrm{R}$ 3.2.3 [12] and graphics application Veusz 1.23.2. The linear-quadratic model was applied to receive dose-survival dependencies (1). The agreement between the experimental data and the model was estimated using the $\chi^{2}$ criterion.

$$
S=100 \cdot \exp \left(-\alpha \cdot D-\beta \cdot D^{2}\right)
$$

where:

$\alpha$ - coefficient related to single-track events,

$\beta$ - coefficient related to two-track events,

$D$ - irradiation dose.

The error of dose measurements was $5 \%$ for gamma-rays and $15 \%$ for carbon ions. The error of cell survival was estimated according to equation 2 and included the errors of hemocytometer ( $a-$ up to $10 \%$ ), micropipettes ( $b-$ up to $3 \%$ ) and Poisson error of grown colony number ( $c-$ up to $5 \%$ ). In case of survival endpoint, the error doubles in accordance with the rule of relative errors summation. The errors of the dose-survival curves obtained by the linear-quadratic model were considered to be equal to $5 \%$; RBE errors in compliance with relative error summation were $10 \%$.

$$
S x=\sqrt{a^{2}+b^{2}+c^{2}}=11.6 \%
$$

\section{RESULTS}

The dependence of melanoma B-16 survival on irradiation dose according to clonogenic assay is shown in Figure 2. The curves are related to gamma-rays and three ranges (A, B and C) of carbon ions. Dose-survival dependencies in case of ranges $\mathrm{A}$ and $\mathrm{B}$ were linear. $\beta$-coefficient for range A (plateau) was minimal, for range $B$ (the peak) equaled $\mathrm{O}$. By contrast, range $\mathrm{C}$ (are after the peak) had a distinct $\beta$-coefficient. The dose 
E. Beketov et al., The study of biological effectiveness..., Rad. Applic., 2017, 2, 2, 90-93

dependence for range $\mathrm{C}$ was linear-quadratic. It is more specific for low-LET radiation than for carbon ions.

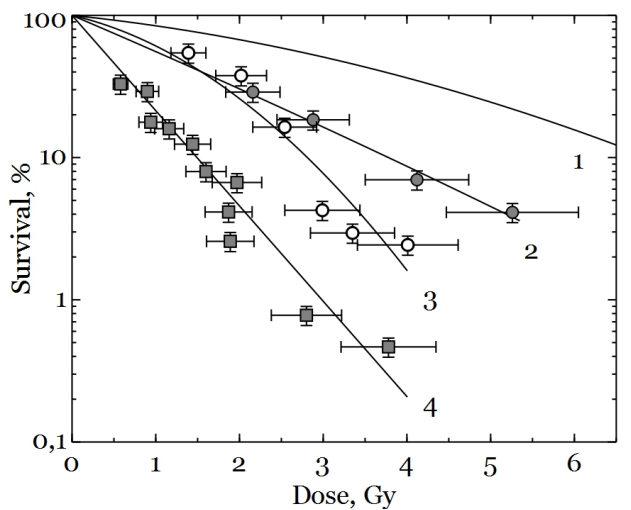

Figure 2. The dependence of melanoma B-16 cell survival on irradiation dose for: gamma-rays (1), carbon ions in range $\mathrm{A}(2, \bullet)$, range $\mathrm{C}(3, \circ)$ and range $\mathrm{B}(4, \boldsymbol{a})$

Linear-quadratic equation coefficients are shown in Table 1. This table is supplemented with findings for fast neutrons published earlier [13-14]. The statistical significance $(*)$ of the coefficients is also shown where possible.

Table 1. Linear-quadratic model coefficient values related to melanoma B-16 cell survival after the irradiation with gamma-rays, carbon ions and fast neutrons

\begin{tabular}{|l|l|l|}
\hline \multicolumn{1}{|c|}{ Radiation } & \multicolumn{1}{c|}{$\alpha \pm S_{x}$} & \multicolumn{1}{c|}{$\beta \pm S_{x}$} \\
\hline Gamma-rays & $0.177 \pm 0.027^{*}$ & $0.025 \pm 0.003^{*}$ \\
Carbon-ions: range A & $0.579 \pm 0.084^{*}$ & $0.007 \pm 0.020$ \\
Carbon-ions: range B & $1.543 \pm 0.283^{*}$ & 0 \\
Carbon-ions: range C & $0.316 \pm 0.250$ & $0.179 \pm 0.095$ \\
$14 \mathrm{MeV}$ neutrons & $0.856 \pm 0.061^{*}$ & $0.001 \pm 0.020$ \\
\hline
\end{tabular}

According to data from Table 1 and Figure 1, RBE values could be determined. The calculated values are shown in Table 2. The estimation was performed for different survival rates: $10,37 \%$ and for survival corresponding $2 \mathrm{~Gy}$ gamma-rays irradiation (conventional daily fraction in radiotherapy). The table is also supplemented with $\alpha$-coefficients ratios (studied radiation / gamma-rays). The last parameter reflects the maximum value of RBE.

Table 2. RBE values related to melanoma B-16 clonogenic assay for carbon ions and fast neutrons

\begin{tabular}{|l|c|c|c|c|}
\hline \multicolumn{1}{|c|}{ Radiation } & $10 \%$ & $37 \%$ & $2 \mathrm{~Gy}$ & $\alpha / \alpha$ \\
\hline Carbon-ions: range A & $1.7 \pm 0.2$ & $2.2 \pm 0.2$ & $2.6 \pm 0.3$ & $3.3 \pm 0.3$ \\
Carbon-ions: range B & $4.5 \pm 0.5$ & $5.7 \pm 0.6$ & $6.8 \pm 0.7$ & $8.7 \pm 0.9$ \\
Carbon-ions: range C & $2.4 \pm 0.2$ & $2.3 \pm 0.2$ & $2.1 \pm 0.2$ & $1.8 \pm 0.2$ \\
$14 \mathrm{MeV}$ neutrons & $2.5 \pm 0.3$ & $3.2 \pm 0.3$ & $3.8 \pm 0.4$ & $4.8 \pm 0.5$ \\
\hline
\end{tabular}

According to Table 2, RBE for range B (Bragg peak) in case of $10 \%$ survival level outweighs 4 units. RBE values for ranges $\mathrm{A}$ and $\mathrm{C}$ were comparable to each other and to fast neutron effectiveness. Depending on the survival level, RBE values of range A and B were growing while RBE was increasing. It reached its maximum value in case of $\mathrm{RBE}$ estimated by $\alpha$-coefficients ratios. By contrast, RBE of the range $\mathrm{C}$ (area after the peak) due to the significant $\beta$-coefficient was falling when survival level was increasing.

\section{DISCUSSION}

$\mathrm{RBE}$ values related to range $\mathrm{A}(1.7$ at $10 \div 16 \mathrm{keV} / \mu \mathrm{m})$ confirm available data. Depending on cell culture and LET $(13-20 \mathrm{keV} / \mu \mathrm{m})$, it varies from 1.5 up to $2.0[4,5,7]$.

In the present study, range B (Bragg peak) was provided by an unmodified (not spread-out) peak with LET on the level of $180 \mathrm{keV} / \mu \mathrm{m}$. The RBE obtained in the experiments was $4.5 \pm 0.5$. This value exceeds data available in literature for the modified (spread-out) peak. The RBE in case of the modified peak is from 2.5 to 3.0 at average LET of $125 \mathrm{keV} / \mu \mathrm{m}[5,7]$ and from 2.3 to 3.6 at $40-44 \mathrm{keV} / \mu \mathrm{m}[4]$.

Unusual linear-quadratic shape of the dose-survival curve in case of range $\mathrm{C}$ was an important part of the study results. Due to certain high-LET nature, all three ranges of the carbon ion radiation should provide linear (in log-scale) shape of survival curves. This effect may be explained by secondary particles forming in the biological tissue [3]. The ratio of doses related to primary radiation (carbon ions) and secondary particles differs sharply in ranges $\mathrm{A}$ and $\mathrm{B}$ and in range $\mathrm{C}$.

The $\mathrm{RBE}$ value obtained in range $\mathrm{C}$ (2.4 units) exceeds RBE values available in literature. In case of LET of about $20 \mathrm{keV} / \mu \mathrm{m}, \mathrm{RBE}$ should be on the level of 1.5 [4]. But this data is related to the plateau area (range A - in the present study) not to the area after the peak. The equality of the LET before and after the peak is a distinctive trait of the charged particles. Therefore, carbon ions provide a unique opportunity to study the influence of the secondary particles forming in the tissue. According to the results of the study, LET could not be considered as the only characteristic of radiation that influences its RBE.

\section{CONCLUSION}

The results obtained in the study require further investigations. It is related to the necessity of more accurate RBE values and RBE-LET dependency. This data will ensure more precise schedules of carbon ion therapy. Another important direction is related to the obtained biological effects of the area after the peak. The results of the present study substantiate its possible significant impact on doses corresponding to normal tissues surrounding the tumor. These issues are tightly associated with radiotherapy efficacy, patient life quality after the treatment and adverse long-term effects.

Acknowledgement: The paper is a part of the collaborative researches conducted by the Medical Radiological Research Center and the Institute for High Energy Physics related to the development and 
preclinical trials of the source for radiotherapy with carbon ions.

\section{REFERENCES}

1. D. Habermehl et al., "The relative biological effectiveness for carbon and oxygen ion beams using the raster-scanning technique in hepatocellular carcinoma cell lines," PLoS One, vol. 9, no. 12, p. e113591, Dec. 2014.

DOI: 10.1371/journal.pone.0113591

PMid: 25460352

PMCid: PMC4252049

2. H. Tsujii et al., "Clinical advantages of carbon-ion radiotherapy," New Journal of Physics, vol. 10, no. 7, pp. 075009-1 - 075009-16, Jul. 2008.

DOI: $10.1088 / 1367-2630 / 10 / 7 / 075009$

3. М. М. Кац, "Сравнение биологического действия пучков протонов и ионов ${ }^{12} \mathrm{C}$ при лучевой терапии," Медицинская физика, т. 2014, № 4, с. 22-25, 2014. (M. M. Kats, "Comparison of Biological impact of proton and ${ }^{12} \mathrm{C}$ ion beams in radiation treatement," Medical Physics, vol. 2014, no. 4, pp. 22-25, 2014.) Retrieved from:

http://medphys.amphr.ru/_private/DB/64_22.pdf Retrieved on: Jan. 19, 2017

4. Н. В. Марков, “Дозиметрия импульсных пучков тяжелых ионов для радиобиологических исследований на ускорительном комплексе ИТЭФ-ТВН,” Дис. к.ф.-м.н., НИЦ «Курчатовский институт» ФГБУ «ГНЦ РФ ИТЭФ», Российская Федерация, 2014

(N. V. Markov, "Dosimetry of pulse beams of heavy ions for radiobiology researches at the ITEP-TVN accelerator complex," Ph.D. Dissertation, Institute for Theoretical and Experimental Physics, Russia, 2014.)

Retrieved from:

http://www.itep.ru/science/dis/candidate dissertation detail.php?ID=223

Retrieved on: Feb. 8, 2017

5. T. Kanai et al., "Biophysical characteristics of HIMAC clinical irradiation system for heavy-ion radiation therapy," International Journal of Radiation Oncology, Biology, Physics, vol. 44, no. 1, pp. 201-210, Apr. 1999.

DOI: 10.1016/So360-3016(98)oo544-6

6. K. Oonishi et al., "Different effects of carbon ion beams and X-rays on clonogenic survival and DNA repair in human pancreatic cancer stem-like cells," Radiotherapy and Oncology, vol. 105, no. 2, pp. 258265, Nov. 2012.

DOI: 10.1016/j.radonc.2012.08.009

PMid: 23017870
7. H. Tsujii et al. "Clinical results of carbon ion radiotherapy at NIRS," Journal of Radiation Research, vol. 48, pp. A1-A13, Mar. 2007. DOI: $10.1269 /$ jrr.48.A1

8. S. Bentzen et al., "Does variation in the in vitro cellular radiosensitivity explain the shallow clinical dosecontrol curve for malignant melanoma?" Int. J. Radiat Biol., vol. 57, no. 1, pp. 117-126, 1990.

DOI: $10.1080 / 09553009014550391$

PMid: 1967283

9. R. Hill et al., "The lung-colony assay: extension to the Lewis lung tumour and the B16 melanomaradiosensitivity of B16 melanoma cells," Int. J. Radiat. Biol. Relat. Stud. Phys. Chem. Med., vol. 27 no. 4 pp. $377-387$, Mar. 1975

DOI: $10.1080 / 0955300751455035$

PMid: 1095507

10. K. Guda et al., "An improved method for staining cell colonies in clonogenic assays," Cytotechnology, vol. 54 no. 2, pp. 85-88, Jun. 2007.

DOI: $10.1007 / \mathrm{s} 10616-007-9083-2$

PMid: 19003022 PMCid: PMC2267497

11. Y. M. Antipov et al., "Transversally-flat dose field formation and primary radiobiological exercises with the carbon beam extracted from the U-70 synchrotron," Instruments and Experimental Techniques, vol. 58, no. 4, pp. 552-561, Jul. 2015. DOI: $10.1134 /$ SoO2O441215040016

12. R Core Team, R Foundation for Statistical Computing, Vienna, Austria, 2016, R: A Language and Environment for Statistical Computing ver. 3.2.3.

Retrieved from: https://cran.r-project.org/src/base/R-3/ Retrieved on: Feb. 8, 2017

13. Е. Е. Бекетов и соавт., “Зависимость эффективности одновременного воздействия гамма-квантов и нейтронов $\mathrm{c}$ энергией 14 МэВ от вклада плотноионизирующего компонента," Радиация u риск, т. 21, № 3, с. 82-90, 2012.

(E. E. Beketov et al., "Dependence of simultaneous exposure of gamma-rays and neutrons with energy $14 \mathrm{MeV}$ effectiveness on high-LET component contribution," Radiation and Risk, vol. 21, no. 3 pp. 82-90, 2012.)

14. E. V. Isaeva et al., "A comparative study of the biological effectiveness of $14-\mathrm{MeV}$ neutron pulse and continuous radiation using mouse melanoma B-16 cells," Radiation Protection Dosimetry, vol. 161, no. 1-4, pp. 478-482, Oct. 2014.

DOI: $10.1093 / \mathrm{rpd} / \mathrm{nct} 247$

PMid: 24101654 